\title{
Optimal Control of a Thermoelectric Generator Attached with a Latent Heat Accumulator
}

\author{
Akira Tsuyoshi \\ Department of Electrical Engineering, Kobe City College of Technology, Kobe, Japan \\ Email: kcct-tsuyoshi@g.kobe-kosen.ac.jp
}

How to cite this paper: Tsuyoshi, A. (2017) Optimal Control of a Thermoelectric Generator Attached with a Latent Heat Accumulator. Journal of Power and Energy Engineering, 5, 1-8. https://doi.org/10.4236/jpee.2017.54001

Received: March 7, 2017

Accepted: April 17, 2017

Published: April 20, 2017

Copyright $\odot 2017$ by author and Scientific Research Publishing Inc. This work is licensed under the Creative Commons Attribution International License (CC BY 4.0).

http://creativecommons.org/licenses/by/4.0/

\section{c) (i) Open Access}

\begin{abstract}
Generally MPPT control (maximum power point tracking) is adopted to control of a thermoelectric generator. However, in the case of generation by use of a heat accumulator MPPT control cannot obtain maximum whole electrical output during the operation period. This is because the amount of heat stored in a heat accumulator is limited and easy to be exhausted rapidly by MPPT. Therefore MEPT (Maximum Efficiency Point Tracking) control should be developed to obtain maximum power from limited heat stored in the heat accumulator. When thermoelectric generator is used for waste heat recovery, conversion efficiency is quite difficult to be measured. This is due to time delay between the change of temperature profile in the thermoelectric generator and the change of heat medium temperature. Decrease of output current is desired to enlarge output because decrease of current decreases Peltier heat and improves efficiency of heat recovery. The experimental results indicate that current fluctuated by MPPT control causes loss of power output. We proposed the optimal control in which current is $10 \%$ smaller than one of MPPT control and evaluated it experimentally. We call this control scheme MEPT control. In this evaluation $500 \mathrm{~W}$ class thermoelectric generator, latent heat accumulator and the test facilities included $30 \mathrm{~kW}$ electric heater are utilized. Experimental result shows MEPT control exceeds MPPT in total electricity recovered from heat accumulator.
\end{abstract}

\section{Keywords}

Thermoelectric Generator, Heat Accumulator, MPPT, MEPT

\section{Introduction}

A thermoelectric generator has been proposed to be applied for waste heat of an incinerator without a damage of thermal stress [1]. However thermoelectric generating system has not been put into practical use yet because their cost, espe- 
cially generating modules cost, is still high. In this paper a heat accumulator installed thermoelectric generating system for the batch operated incinerator was proposed and experimentally investigated. A heat accumulator has the potential to reduce cost of thermoelectric generating system by reduction of a capacity of employed thermoelectric generating modules. However optimal control of the thermoelectric generator attached with a heat accumulator has not been developed yet. The MPPT (Maximum Power Point Tracking) control accelerates the drop in the heat medium temperature by Peltier effect so that it cannot supply maximum electricity from heat stored in the heat accumulator. We proposed MEPT (Maximum Efficiency Point Tracking) control as an optimal control which electricity could be obtained from a heat accumulator more effectively than MPPT control.

\section{Effect of a Heat Accumulator}

\subsection{Introduction of a Heat Accumulator into a Garbage Plant}

In ordinary large scale garbage plants which dispose more than 200 [ton/day] combustible waste, conventional steam turbine generators are utilized for waste heat recovery. However a steam turbine generator is not applicable to a smaller scale garbage plant which is operated intermittently. Even in such cases thermoelectric generators can be applied. In this paper application of a thermoelectric generator for small scale garbage incinerator was studied. For design of thermoelectric generator it is necessary to estimate a capacity of thermoelectric generator. If all of heat generated in an incinerator is used for thermoelectric generation, generator capacity should amount to peak value of waste heat generation as shown Figure 1. However an excess of capacity of generator increase initial cost and generating cost. Therefore a heat accumulator which can deal with peak value of waste heat generation is effective to decrease initial cost and generating cost [2].

As shown in Figure 2 a heat accumulator is proposed to be utilized for thermoelectric generation for heat recovery of waste heat in such incinerator so that the capacity of the thermoelectric generator and also the initial cost can be reduced. The excess waste heat which is more than the capacity of the thermoelectric generator is stored in the heat accumulator. The stored heat is used when

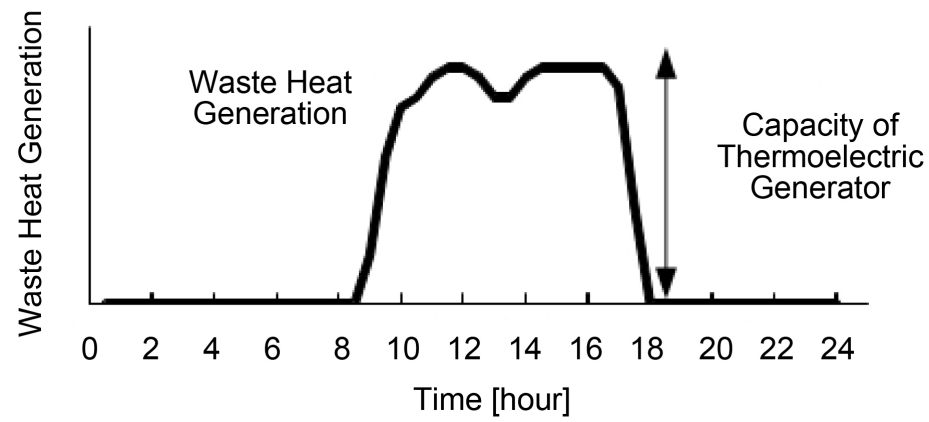

Figure 1. Hourly variation of waste heat generation. 


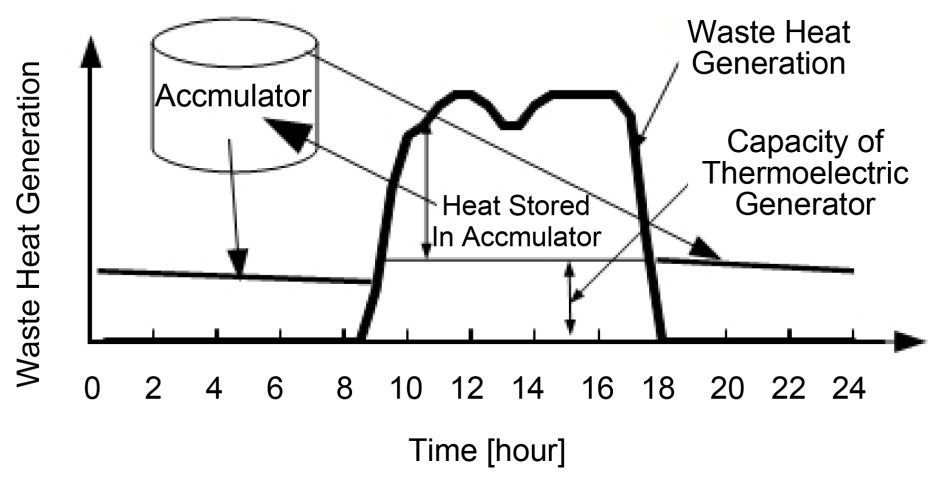

Figure 2. Hourly variation of waste heat generation and heat transfer with an accumulator.

waste heat generation is smaller than the capacity of the thermoelectric generator.

\subsection{Latent Heat Accumulator}

There are two types of heat accumulators: sensible heat storage and latent heat storage. Latent heat storage employs PCM (Phase Change Material) as heat storage medium. A latent heat accumulator is more suitable for thermoelectric generation because stable operation temperature around melting point can help to achieve high conversion efficiency. Therefore the efficiency of thermoelectric generation is proportional to the temperature difference between heating medium and cooling medium. Table 1 shows properties of PCM of middle range of temperature. We employed $\mathrm{KOH}-\mathrm{NaOH}$ eutectic mixture as heat storage material in our experiment. Melting point of $\mathrm{KOH}-\mathrm{NaOH}$ is $170 \mathrm{degC}$ suitable for employed thermoelectric generator and commercially available as industrial raw material.

\section{Experimental Evaluation of Latent Heat Storage Thermoelectric Generation}

\subsection{Experimental Facilities}

The experimental facility which consists of the heat accumulator which employs $\mathrm{KOH}-\mathrm{NaOH}$ eutectic mixture, heat medium oil heating and circulating system which employs $25 \mathrm{kWe}$ class electric heater, water cooler and $500 \mathrm{~W}$ class thermoelectric generator is schematically shown in Figure 3. The specifications of the employed thermoelectric generator are shown in Table 2.

The electric heater employed in heat medium oil heating and circulating system imitates waste heat generation. When the heater is switched off, heat stored in the heat accumulator is supplied as heat source of the thermoelectric generation for heat discharged mode.

Figure 4 shows the experimental results when inlet temperatures of heat medium oil and cooling water are $250[\operatorname{deg} \mathrm{C}]$ and $25[\operatorname{deg} \mathrm{C}]$ respectively, and flow rates of heat medium oil and cooling water and $18[\mathrm{liter} / \mathrm{m}]$ and $20[\mathrm{liter} / \mathrm{m}]$ respectively. For safety reason, the temperature and the flow rate of heat medium 
Table 1. Properties of phase change material of intermediate-temperature [3] [4].

\begin{tabular}{|c|c|c|c|}
\hline Phase Change Material & Composition & Melting Points & Heat of Fusion \\
\hline & & {$[\operatorname{deg} C]$} & $(\mathrm{kJ} / \mathrm{kg})$ \\
\hline Polyethylene & - & 135 & 209 \\
\hline $\mathrm{KOH}-\mathrm{NaOH}$ & $50-50$ & 170 & 231 \\
\hline Pentaerythritol & - & 188 & 322 \\
\hline $\mathrm{LiOH}-\mathrm{NaOH}$ & $30-70$ & 210 & 362 \\
\hline $\mathrm{KOH}-\mathrm{LiOH}$ & $71-29$ & 227 & 273 \\
\hline $\mathrm{NaNO}_{2}-\mathrm{NaOH}$ & $27-73$ & 239 & 279 \\
\hline $\mathrm{LiNO}_{3}$ & - & 250 & 370 \\
\hline $\mathrm{NaNO}_{3}-\mathrm{NaOH}$ & $19-81$ & 258 & 296 \\
\hline LiCl-LiOH & $37-63$ & 262 & 453 \\
\hline $\mathrm{Na}_{2} \mathrm{CO}_{3} \mathrm{NaOH}$ & $7.2-92.8$ & 283 & 324 \\
\hline
\end{tabular}

Table 2. Thermoelectric generator specification.

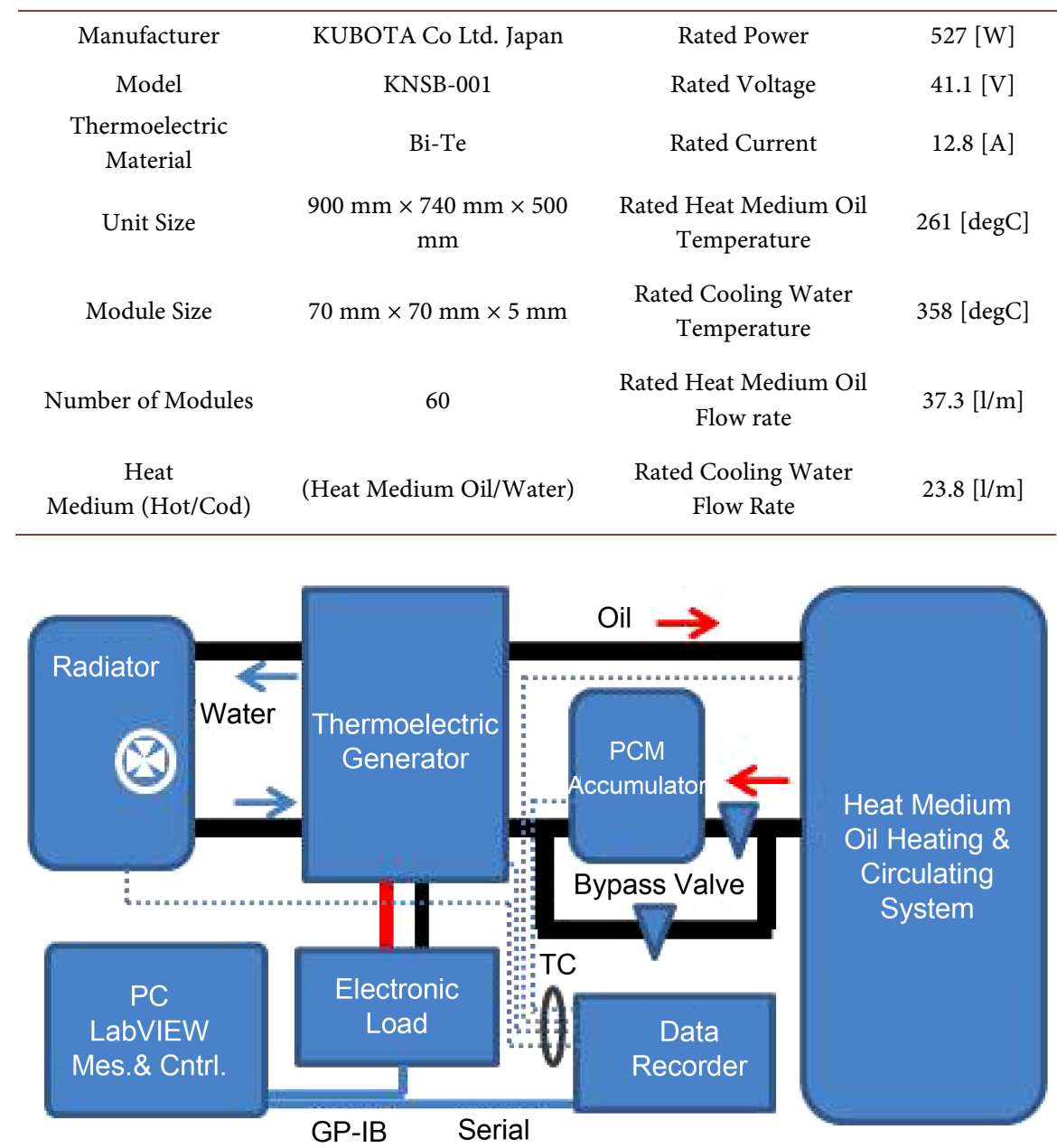

Figure 3. Experimental facilities.

oil are reduced from rated values. When the thermoelectric generator has the equivalent circuit that is connected the constant voltage source and the constant 


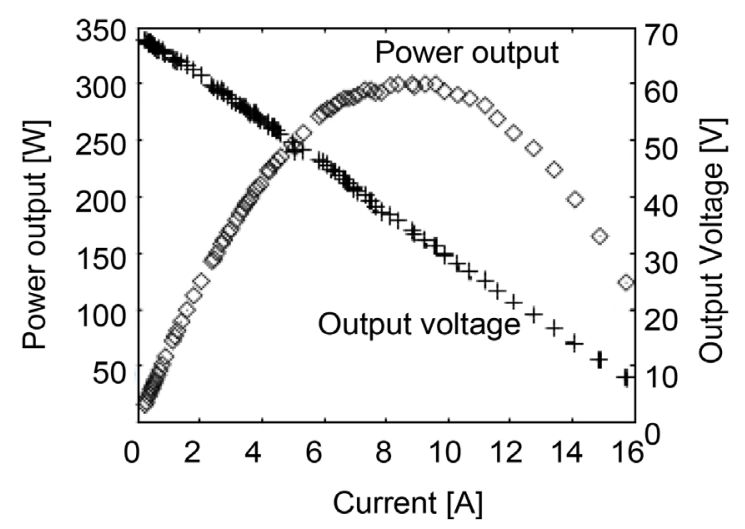

Figure 4. Experimental results.

resistance, the Voltage-Current characteristics shows straight line and the Output-Current characteristics shows parabola. However as a result shown in Figure $4 \mathrm{~V}$-I curve is not straight and P-I curve is not parabola. The peak area where the maximum power is obtained in P-I curve is slightly broad. This is because the properties of the modules connected in series and parallel vary according to temperature profile in the thermoelectric generator.

\subsection{MPPT Control of a Thermoelectric Generator}

Generally a thermoelectric generator is controlled by MPPT which is realized by hill climbing method. But current control based MPPT control employed for photovoltaic is not suitable for the large scale thermoelectric generator which has broad peak. This is because it is difficult to determine the adequate current control step which depends on temperature difference. So load resistance was proposed to be used for control parameter for MPPT control.

Figure 5 shows variation of MPPT controlled load resistance in variation of temperature of heat source. Load resistance is suitable for the MPPT control parameter because controlled load resistance fluctuates for almost same width in any heat source temperature as shown Figure 5. Load resistance controlled for maximum power increases from $3[\mathrm{ohm}]$ to $4[\mathrm{ohm}]$ when heat source temperature increases from $50[\operatorname{deg} C]$ to $250[\operatorname{degC}]$.

\subsection{Proposed Optimal Control of a Thermoelectric Generator}

As mentioned above, even in the steady state operation, the control width is $10 \%$ of load resistance. When thermoelectric generator is operated by stored heat in discharged mode, controlled load resistance fluctuates more than $10 \%$. In discharge mode heat source temperature decreases and it is more difficult to determine the maximum power point. Therefore, in such a case, an excess control to the lower load resistant causes significant increase of Peltier heat and acceleration of consumption of stored heat in the heat accumulator. For the reasons mentioned above it is reported that MPPT control cannot obtain the maximum electricity from limited energy stored in the heat accumulator. [5] Therefore we proposed MEPT (Maximum Efficiency Point Tracking) control to obtain the 
maximum electricity from limited energy. But when using limited energy stored in an accumulator heat source temperature is not constant and decrease gradually, so that it is difficult to determine the maximum efficiency point exactly.

Efficiency and power of the large scale thermoelectric generator was theoretically calculated as shown in Figure 6. This calculation is based on the condition that inlet temperatures of heat medium oil and cooling water are $220[\mathrm{degC}]$ and $25[\mathrm{degC}]$ respectively, and flow rates of heat medium oil and cooling water and $18[\mathrm{liter} / \mathrm{m}]$ and $20[\mathrm{liter} / \mathrm{m}]$ respectively.

Figure 6 shows that the current at the maximum efficiency point is 7.5 [A]. This is about $10 \%$ smaller than the current at the maximum power point. Therefore we proposed that maximum efficiency point should be determined as the point where the load resistance is $20 \%$ larger than the matching load.

\subsection{Experimental Evaluation of MEPT Control}

Proposed MEPT control was experimentally evaluated compared to MPPT control. Typical results are shown in Figure 7. A significant difference between MPPT control and MEPT control was not observed in their inlet temperatures. But obviously MEPT control exceeds MPPT control in recovered electrical

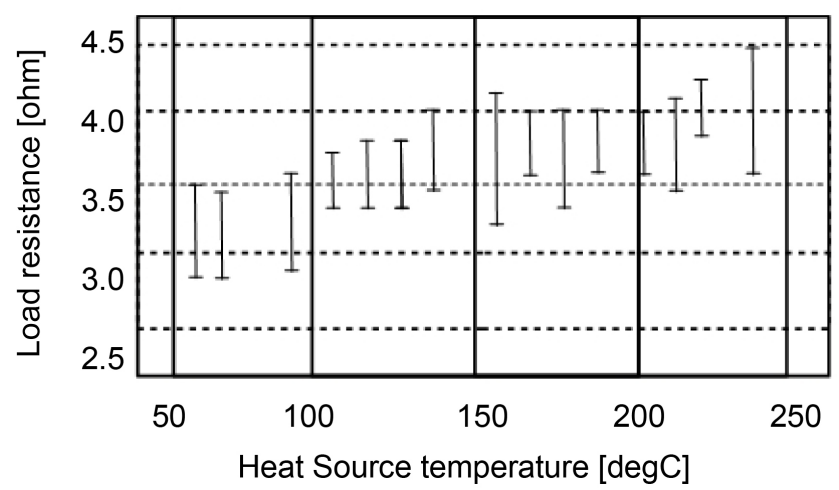

Figure 5. MPPT controlled load resistance.

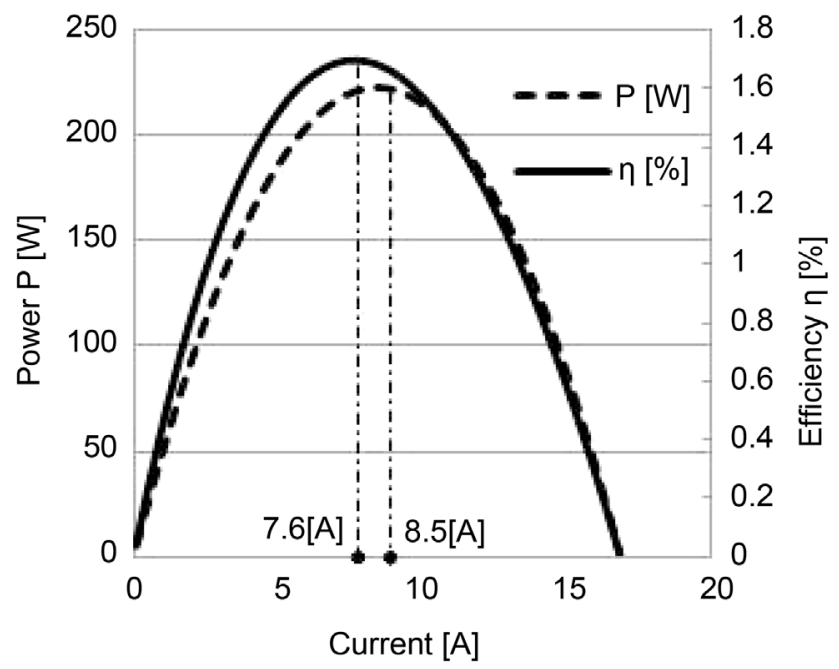

Figure 6. Theoretical power and efficiency vs current. 


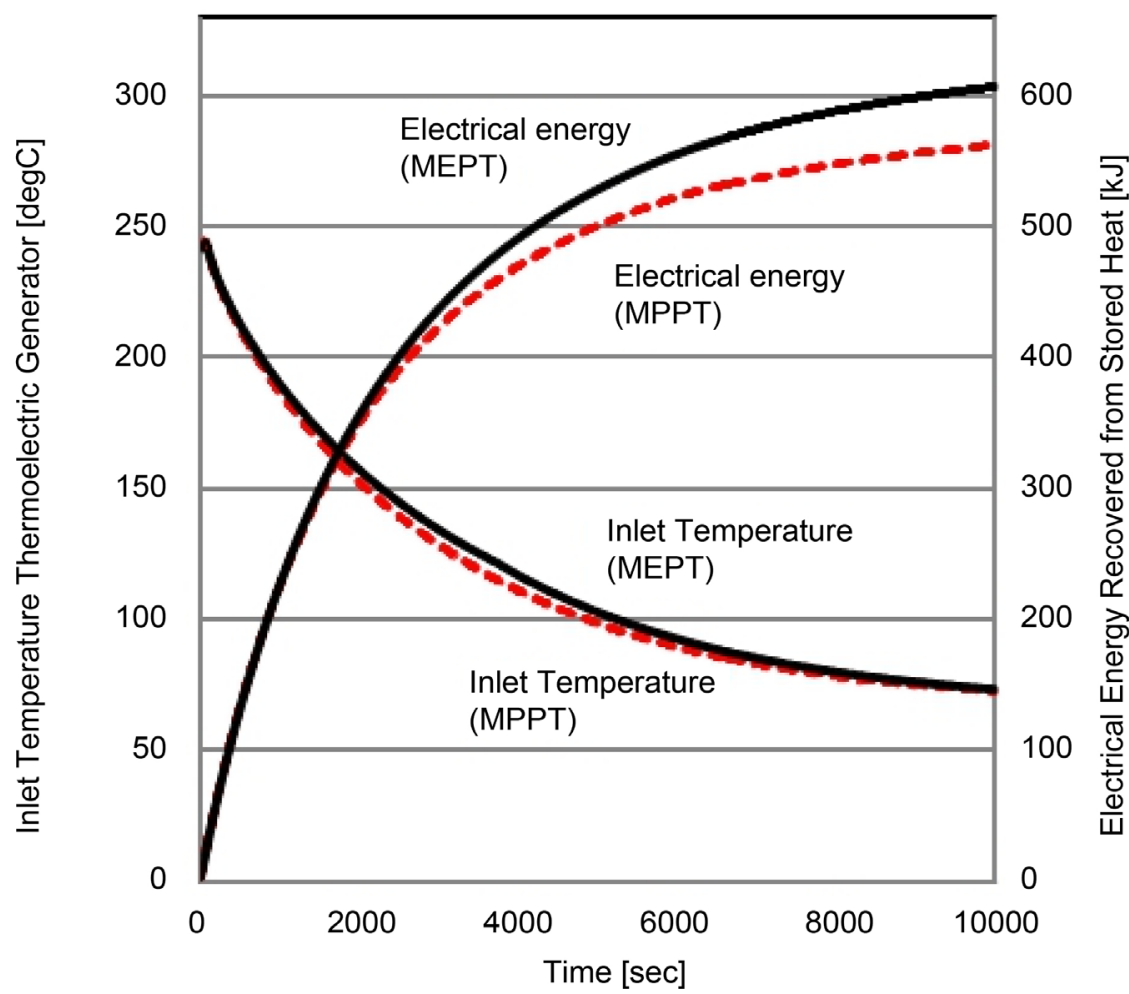

Figure 7. Recovered electrical energy and inlet temperature vs current.

energy. During 1000 [sec] operation MPPT control and MPET control obtained $563[\mathrm{~kJ}]$ and $607[\mathrm{~kJ}]$ respectively.

\section{Conclusions}

In this study optimum control of a thermoelectric generator attached with a latent heat accumulator was proposed and experimentally evaluated. The obtained results are as follows:

1) Load resistance controlled for maximum power increases from 3 [ohm] to $4[\mathrm{ohm}]$ when heat source temperature increases from $50[\mathrm{degC}]$ to $250[\mathrm{degC}]$.

2) MEPT control current is $10 \%$ smaller than MPPT control current.

3) MEPT control exceeds MPPT control in recovered electrical energy.

\section{References}

[1] Kajikawa, T., et al. (1993) Conceptual Design of Thermoelectric Power Generation System Using the Waste Heat of Combustible Solid Waste. Proceedings of the 12 th International Conference on Thermoelectrics, Yokohama, 7-10 November 1993, 491-496.

[2] Tsuyoshi, A. and Matsuura, K. (2007) Effect of Introduction of a Heat Accumulator of Performance of Thermoelectric Generation. IEEJ Transactions on Power and Energy, 120, 1699-1705.

[3] Ozaw, T., Kamimoto, M., et al. (1980) Preliminary Investigation of PCM (1). Bulletin of the Electrotechnical Laboratory, 44, 707-724.

[4] Tanaka, K., Kanenari, K. et al. (1987) Preliminary Investigation of PCM (3). Bulletin of the Electrotechnical Laboratory, 51, 469-483.

[5] Tsuyoshi, A., Michihira, M. and Kato, S. (2007) The Energy Recovery System of Unused 
Thermal Energy by Using the Thermoelectric Generator. IEEJ, Proceedings of 2017 IEE-Japan Industry Application Society Conference, 1-O7-1, Osaka, 20-22 August 2007, 137-140.

Submit or recommend next manuscript to SCIRP and we will provide best service for you:

Accepting pre-submission inquiries through Email, Facebook, LinkedIn, Twitter, etc. A wide selection of journals (inclusive of 9 subjects, more than 200 journals)

Providing 24-hour high-quality service

User-friendly online submission system

Fair and swift peer-review system

Efficient typesetting and proofreading procedure

Display of the result of downloads and visits, as well as the number of cited articles Maximum dissemination of your research work

Submit your manuscript at: http://papersubmission.scirp.org/

Or contact jpee@scirp.org 